International Journal of Health Sciences
Available online at www.Sciencescholar.us
Vol. 5 No. 3, December 2021, pages: $260-275$
e-ISSN: 2550-696X, p-ISSN: 2550-6978
https://doi.org/10.53730/ijhs.v5n3.1495

\title{
Clinical-Functional and Morphological Parameters of Purulonecrotic Foci Healing in Diabetic Foot Syndrome Using Programmable Sanitation Technologies
}

\author{
CrossMark \\ Vladimir A. Sergeev a, Alexander A. Glukhov ${ }^{\text {b }}$, Alexander S. Sorokin c, Sergey A. Zhuchkov d, \\ Alexander V. Gorokhov ${ }^{\text {, Elena N. Troshkina }}{ }^{f}$ \\ Manuscript submitted: 18 May 2021, Manuscript revised: 09 August 2021, Accepted for publication: 8 September 2021
}

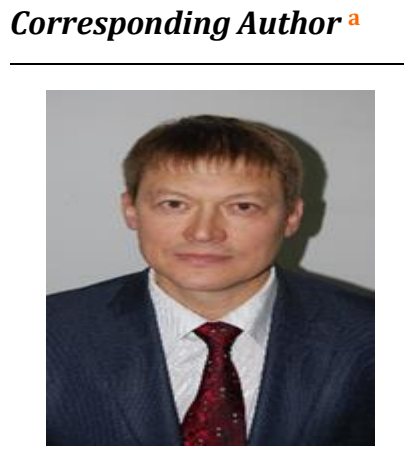

Keywords

complications;

cytological examination;

diabetes mellitus;

health care;

patients;

reparative process;

\begin{abstract}
Diabetes mellitus is currently characterized by a high progressive prevalence of patients. The purpose of this study is to evaluate the clinical, functional, and morphological parameters of purulonecrotic foci healing in diabetic foot syndrome (DFS) using programmable sanitation technologies. The patients were randomized into two groups. In the comparison group $(n=51)$, patients received conventional local treatment after surgery. In the main group $(n=55)$, after surgical treatment, the wound was sutured, and in the postsurgical period, programmable sanitation was conducted using the AMP-01 device. The cytological smears of the main group identified a higher rate of cellular reactions in the wound. There was a 1.3-fold reduction in the duration of hospitalization, the number of purulent complications was significantly less $(p=0.014)$. It was possible to preserve the supporting function of the foot in patients of the main group in a larger percentage of cases $(p=0.023)$. There was a statistically significant increase in the frequency of high amputations in the comparison group $(p=0.026)$. As a result, the effectiveness of the use of programmable sanitation technologies for purulent lesions of the diabetic foot has been proven.
\end{abstract}

\footnotetext{
a Orel State University named after I.S. Turgenev, Orel, Russian Federation

b Voronezh State Medical University named after N.N. Burdenko, Voronezh, Russian Federation

c Plekhanov Russian University of Economics, Moscow, Russian Federation

d Orel State University named after I.S. Turgenev, Orel, Russian Federation

e Orel State University named after I.S. Turgenev, Orel, Russian Federation

f Orel Cancer Dispensary, Oryol, Russian Federation
} 


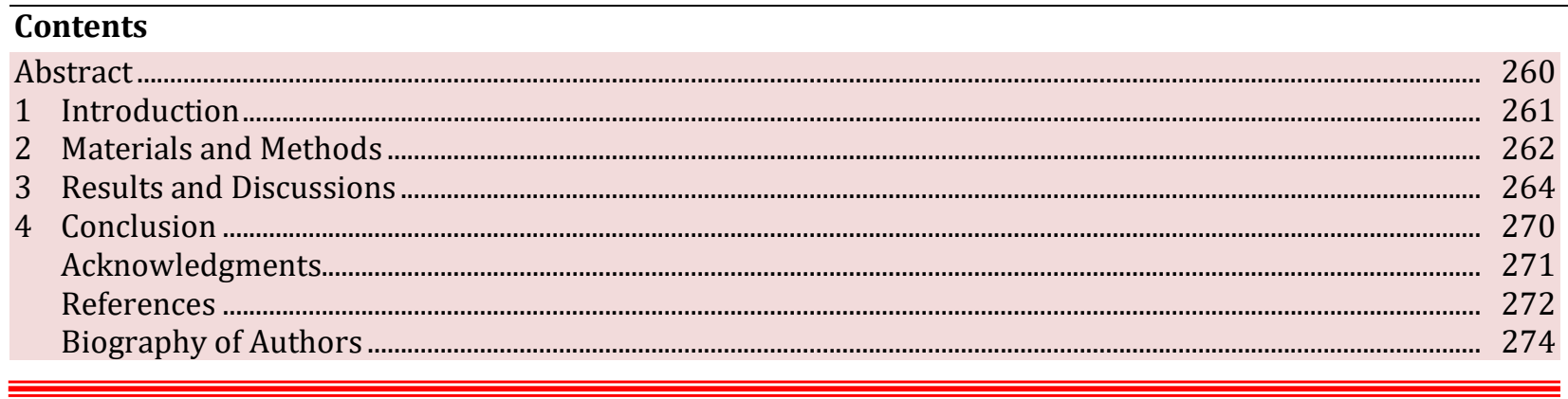

\section{Introduction}

The problem of diabetes mellitus (DM) is currently acquiring medical and social importance, which is explained by the high progressive prevalence, considerable disability, and increased mortality of patients with diabetes (Galstyan et al., 2018; Dedov et al., 2017; Mitish et al., 2014; Bakker et al., 2016). Currently, approximately 285 million people suffer from diabetes, and by 2035, experts predict an increase in the number of patients with DM to 600 million people (Galstyan et al., 2018; Dedov et al., 2017; Stupin et al., 2019). In the United States, DM affects approximately 9.4\% of the population over the age of 18 (National Diabetes Statistics Report, 2014). In 2013, the health care costs associated with DM cost the US budget 548 billion US dollars, which accounted for $11 \%$ of the total health care costs for adults, and by 2035 they are predicted to exceed 627 billion US dollars (Guariguata et al., 2011). Every year in the world, complications of DM become the cause of death in 1.6 million people, and, according to experts, this figure will double in 10 years (Bordianu et al., 2018). Approximately 25\% of diabetics are at risk of developing diabetic foot ulcer (DFU), which is the main reason for their hospitalisation, which costs the US 40,000 dollars per event (Ray et al., 2005; Armstrong et al., 2017; Jang et al., 2015).

It is possible to heal diabetic ulcers by conservative measures only in $63-81 \%$ of cases, amputation of various levels of the limb is required in $14-24 \%$ of patients, while mortality rates reach $13 \%$. These figures emphasise the need to find innovative approaches to the problem of treating purulonecrotic complications of DM (Nickerson, 2018; Ivanov et al., 2019). Most specialists consider the conservative approach to their treatment to be the main and determining one, but the duration of such therapy is many months. At the same time, invasive methods of treatment are expensive, and standard schemes of local drug therapy of wound and ulcerative defects are ineffective (Mitish et al., 2014; Bordianu et al., 2018; Yusupova et al., 2017). The slowing down of the healing processes in purulent lesions of DM is due to the presence of polyneuropathy, angiopathy, osteoarthropathy, which are interrelated factors and lead to the development of terrible complications. These complications often lead to the loss of a limb and sometimes pose a real threat to the patient's life (Armstrong et al., 2017; Braun et al., 2014). Over the past decade, thanks to fundamental scientific research in the field of molecular cell biology, a more complete understanding of the main mechanisms of wound healing in diabetes have become possible. At the same time, there is a violation of the synthesis of growth factors due to a decrease in the activity of macrophages. The role of inflammatory cytokines and matrix metalloproteases in reducing the rate of remodeling of the extracellular matrix and the rate of collagen accumulation has been proven (Zaytseva et al., 2014; Baltzis et al., 2014; Liu et al., 2009; Li et al., 2013; Dinh et al., 2012; Brancato \& Albina, 2011). These and several other pathophysiological mechanisms lead to a chronic prolonged course of wound defects in diabetes with a slowdown in their healing time.

Today, the solution of problems of predicting the course of reparative processes underlying the structural and functional restoration of altered tissues is becoming more and more popular. In this regard, there is an urgent interest in the development of both new approaches to treatment and methods for assessing the dynamics of wound defect healing in DFS (Eskes et al., 2011; Zemskov et al., 2011; Lacci \& Dardik, 2010; Han, Wang \& Zang, 2012; Larichev et al., 2011). The purpose of this study is to evaluate the clinical, functional, and morphological parameters of purulonecrotic foci healing in diabetic foot syndrome (DFS) using programmable sanitation technologies.

Sergeev, V. A., Glukhov, A. A., Sorokin, A. S., Zhuchkov, S. A., Gorokhov, A. V., \& Troshkina, E. N. (2021). Clinical-functional and morphological parameters of purulonecrotic foci healing in diabetic foot syndrome using programmable sanitation technologies. International Journal of Health Sciences, 5(3), 260-275. https://doi.org/10.53730/ijhs.v5n3.1495 


\section{Materials and Methods}

The results of treatment of 106 patients with purulonecrotic complications in diabetic foot syndrome (DFS) without critical ischemia, who were treated at the Orel Regional Clinical Hospital for the period 2008-2018, were analyzed. This study was conducted by the requirements of the Helsinki Declaration of World Medical Practice (as amended in 2013). Inclusion criteria: patients with type 1 and type 2 diabetes mellitus, the absence of critical limb ischemia at TcPO2 values not lower than $27 \mathrm{~mm} \mathrm{Hg}$, the degree of foot tissue damage according to Wagner (1979), of II-IV degree, signed informed consent. The study did not include patients younger than 18 years old, with Wagner I and V degree of DFS, with a TcPO2 index in the foot skin below 27 $\mathrm{mm} \mathrm{Hg}$, with the presence of extensive skin defects in the surgical treatment area. The presence of malignant neoplasms, concomitant diseases in the decompensation stage, circulatory insufficiency and respiratory insufficiency of the III degree, endocrine-metabolic and cerebral obesity, drug addiction, pregnancy, and lactation were also the exclusion criteria.

The patients included in the study, depending on the methods of rehabilitation of purulent foci in the postsurgical period, were randomized into two groups. The comparison group included $51(48.1 \%)$ patients (23 men and 28 women), after surgical treatment of a purulent focus they received conventional local treatment using solutions of iodophores, ointments based on polyethylene glycol, and after the inflammation was stopped, plastic reconstruction of the foot was performed or the wound was healed by secondary tension. The main group consisted of 55 (51.9\%) patients ( 25 men and 30 women), after surgical treatment of a purulent focus tubular drains were installed in the wound cavity, brought out through separate incisions, and the wound was sutured. The drains were connected to the original AMP-01 device (utility model patent No. 176572 dated 10.03.2017) (Sergeev, 2018), with the help of which programmable sanitation was carried out in the postsurgical period. On the control unit of the device, an individually selected program of cyclic irrigation processes, antiseptic aspiration, and constant vacuuming, carried out in an autonomous mode, was installed. The set vacuum level in the purulent cavity was maintained using a built-in pressure sensor.

To evaluate the parameters for the study groups, the mean $(M)$ and standard deviation $(M \pm \sigma)$, median $(\mathrm{Me})$, first and third quartiles (Q1, Q3) were used. In the main group, the age of patients was $59 \pm 8$ years, and

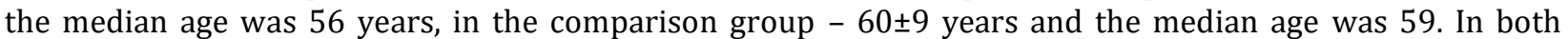
groups, patients with the second type of DM prevailed - 97 (91.5\%) people, the average duration of the course of DM was $12.4 \pm 7.2$ years. There were $9(8.5 \%)$ patients with type 1 of DM, the average duration of DM was $24.8 \pm 8.8$ years. In $88.7 \%$ of cases, patients were hospitalized with decompensated diabetes, and in $6.6 \%$ of cases, primary-detected DM was diagnosed. In $92.5 \%$ of cases, patients were admitted to the hospital for emergency indications, and in $28.3 \%$ of cases, they had a severe degree of intoxication with signs of a systemic inflammatory reaction syndrome (Ceriello, 2006; Koziel \& Koziel, 1995).

According to the clinical form of DFS, the patients were distributed as follows: the neuropathic form of DFS - $63(59.4 \%)$ patients, the neuroischemic form of DFS - $43(40.6 \%)$ patients. At the moment of randomization, all the studied patients had a decrease in the index of partial oxygen tension in the foot skin, and the average values of TcPO2 for clinical forms of DFS were not lower than $27 \mathrm{~mm} \mathrm{Hg}$. The median value of TcPO2 in the foot skin with neuropathic form in the main group was $32.8(32.3 ; 34.8) \mathrm{mm} \mathrm{Hg}$. In the comparison group $33.2(32.2 ; 34.8) \mathrm{mm} \mathrm{Hg}$. In the neuroischemic form, the value of TcPO2 in the foot skin in the main group was $28.8(27.8 ; 29.4) \mathrm{mm} \mathrm{Hg}$, in the comparison group - $28.6(27.8 ; 29.4) \mathrm{mm} \mathrm{Hg}$. The groups of patients were comparable in age, gender, type of DM, and clinical form of DFS (Table 1).

Table 1

Distribution of patients in the study groups by age, gender, type of DM, and clinical form of DFS

\begin{tabular}{|c|c|c|c|c|}
\hline \multicolumn{2}{|l|}{ Indicator } & $\begin{array}{l}\text { Main group } \\
(n=55)\end{array}$ & $\begin{array}{l}\text { Comparison group } \\
(n=51)\end{array}$ & $\begin{array}{l}\mathrm{p} \text { is the significance value of the } \\
\text { differences between the groups }\end{array}$ \\
\hline \multicolumn{2}{|c|}{ Average age, $\mathrm{M} \pm \sigma$} & $59 \pm 8$ & $60 \pm 9$ & $0.26^{*}$ \\
\hline \multirow[t]{2}{*}{ Gender } & men $(n, \%)$ & 25 (45.5\%) & $23(45.1 \%)$ & $1.00^{* *}$ \\
\hline & women $(n, \%)$ & 30 (54.5\%) & 28 (54.9\%) & \\
\hline Type of DM & $\begin{array}{l}\text { 1st type } \\
\text { 2nd type }\end{array}$ & $\begin{array}{l}5(9.1 \%) \\
50(90.9 \%)\end{array}$ & $\begin{array}{l}4(7.8 \%) \\
47(92.2 \%)\end{array}$ & $1.00^{* *}$ \\
\hline
\end{tabular}




\begin{tabular}{|c|c|c|c|c|}
\hline $\begin{array}{l}\text { Form of } \\
\text { DFS }\end{array}$ & $\begin{array}{l}\text { neuropathic } \\
\text { neuroishemic }\end{array}$ & $\begin{array}{l}32(58.2 \%) \\
23(41.8 \%)\end{array}$ & $\begin{array}{l}31(60 \%) \\
20(39,2 \%)\end{array}$ & $0.66^{* *}$ \\
\hline
\end{tabular}

In $75.5 \%$ of cases, the osteoarticular apparatus of the foot was involved in the purulent-destructive process. In $27(25.5 \%)$ cases, there were purulonecrotic and purulent-granulating wounds after finger amputations or foot resection performed in other medical institutions (Carchi et al., 2021; Kurtieva et al., 2021). Tissue damage in the form of dry gangrene was in 21 (19.8\%) patients, and in the form of phlegmon, wet gangrene in $15(14.2 \%)$ patients. The dependence of the distribution of patients according to the nosological form of purulonecrotic complications in DFS and the volume of the lesion in the studied groups was not found $(\times 2$ Pearson criterion $\mathrm{p}=0.989$ ). The distribution of patients of the studied groups depending on the nosological form of purulonecrotic complications in DFS and the volume of the lesion according to the classification of F. Wagner (1979) are presented in Table 2.

Table 2

Distribution of patients of the studied groups depending on the nosological form of purulonecrotic complications of DFS and the volume of the lesion according to the classification of F. Wagner

\begin{tabular}{|c|c|c|c|c|c|c|}
\hline \multirow[t]{2}{*}{$\begin{array}{l}\text { Nosological form of purulonecrotic } \\
\text { process on the foot }\end{array}$} & \multirow[t]{2}{*}{$\begin{array}{l}\text { The volume of the lesion in } \\
\text { accordance with the F. } \\
\text { Wagner classification }\end{array}$} & \multicolumn{2}{|c|}{$\begin{array}{l}\text { Main group } \\
(n=55)\end{array}$} & \multicolumn{2}{|c|}{$\begin{array}{l}\text { Comparison } \\
\text { group } \\
(n=51)\end{array}$} & \multirow[t]{2}{*}{ Total } \\
\hline & & $n$ & $\%$ & $n$ & $\%$ & \\
\hline Hollow ulcer & 2 & 5 & 9.1 & 4 & 7.8 & 9 \\
\hline $\begin{array}{l}\text { Hollow ulcer + chronic osteomyelitis of } \\
\text { the finger }\end{array}$ & 3 & 3 & 5.5 & 3 & 5.9 & 6 \\
\hline Finger phlegmon + foot phlegmon & 2 & 5 & 9.1 & 6 & 11.8 & 11 \\
\hline Finger osteomyelitis + foot phlegmon & 3 & 8 & 14.5 & 9 & 17.6 & 17 \\
\hline $\begin{array}{l}\text { A purulent wound after amputation of } \\
\text { the fingers or resection of the foot } \\
\text { previously performed in other medical } \\
\text { institutions }\end{array}$ & 3 & 14 & 25.5 & 13 & 25.5 & 27 \\
\hline Dry gangrene of one or more fingers & 4 & 12 & 21.8 & 9 & 17.6 & 21 \\
\hline $\begin{array}{l}\text { Wet gangrene of the finger }+ \text { foot } \\
\text { phlegmon }\end{array}$ & 4 & 8 & 14.5 & 7 & 13.7 & 15 \\
\hline Total: & & 55 & 100 & 51 & 100 & 106 \\
\hline
\end{tabular}

In the main group of patients with neuropathic form, radical surgery and plastic reconstruction of the foot were performed in one stage. In the neuroishemic form, staging sanitation of the purulent focus was performed, and after the inflammation was stopped, plastic reconstruction of the foot was performed. In all cases, in the postsurgical period, after suturing the wound, programmable sanitation was used. Patients of the studied groups received complex therapy, which included complete foot unloading, insulin therapy with fractional administration of adequate doses of the drug under the control of glycemia level, etiotropic antibiotic therapy, anticoagulants, and immunomodulators were prescribed according to the indications (Zimny et al., 2002; Duzgun et al., 2008; Falanga, 2005). Perfusion vascular therapy was prescribed to patients with the neuroischemic form of DFS. The primary surgeries in patients in the study groups are presented in Table 3. According to Pearson's $x 2$ test, there are no differences between the groups $(p=0.72)$.

Sergeev, V. A., Glukhov, A. A., Sorokin, A. S., Zhuchkov, S. A., Gorokhov, A. V., \& Troshkina, E. N. (2021). Clinical-functional and morphological parameters of purulonecrotic foci healing in diabetic foot syndrome using programmable sanitation technologies. International Journal of Health Sciences, 5(3), 260-275. https://doi.org/10.53730/ijhs.v5n3.1495 
Table 3

Primary surgeries in patients of the studied groups

\begin{tabular}{llllll}
\hline \multirow{2}{*}{ Primary surgeries } & \multicolumn{2}{l}{ Main group } & \multicolumn{2}{l}{ Comparison group } \\
& $(n=55)$ & & \multicolumn{2}{c}{ Total } \\
\cline { 2 - 5 } & $n$ & $\%$ & $n$ & $\%$ & \\
\hline Surgical debridement & 9 & 16.4 & 9 & 17.6 & 18 \\
Prosection of the phlegmon & 13 & 23.6 & 18 & 35.3 & 31 \\
Amputation of fingers & 9 & 16.4 & 6 & 11.8 & 15 \\
Amputation of the distal segment of the foot & 12 & 21.8 & 8 & 15.7 & 20 \\
Transmetatarsal amputation of the foot & 12 & 21.8 & 10 & 19.6 & 22 \\
Total: & 55 & 100 & 51 & 100 & 106 \\
\hline
\end{tabular}

All patients underwent laboratory tests, radiography of the feet in two projections, ultrasound Doppler examination of the arteries of the lower extremities, transcutaneous oximetry on the TSM 400 device of the "Radiometer medical" company (Denmark). The results of treatment were studied throughout the entire period of hospitalization with evaluation points on the day of admission, as well as on 3, 5, 7, 9, 12 days from the moment of admission to the hospital. The effectiveness of the rehabilitation of purulonecrotic foci in patients with DFS was evaluated by the level of bacterial contamination, $\mathrm{pH}$-metry of the wound discharge. The qualitative parameters of the microflora were evaluated by the disk method by the taxonomic characteristics according to Nemec (2003), and the quantitative characteristics were determined by counting the number of colony-forming units in $1 \mathrm{ml}$ of wound fluid ( $\mathrm{cfu} / \mathrm{ml}$ ). The $\mathrm{pH}$ of the wound exudate was determined using a universal indicator paper of the company "PLIVA-Lachema" (Czech Republic) with a $\mathrm{pH}$ range of 3.9-8.1 with a step of $0.3 \mathrm{pH}$ units. The immediate results of treatment were evaluated by the terms of inpatient treatment, the level of postsurgical mortality, the number of purulent complications, cases of preservation of the supporting function of the foot, and the number of high amputations performed.

To assess the healing of purulent foci of the diabetic foot, a cytological method of examination was used (Kuzin \& Kostyuchenok, 1990). In the comparison group, the sampling of cellular and tissue elements from a purulent wound was carried out by the method of surface biopsy according to M. Pokrovskaya and M. Makarov in the modification of Kamayev (1954), in the main group, the material was taken by the method of "puncture biopsy". The resulting material was stained according to the May-Grunwald-Romanovsky-Giemsa method. The calculation of the shaped elements was carried out using an Axio A1 light microscope (Zeiss, Germany) with an increase of 630 times, while the average indicator for 10 fields of view was output, and the resulting value was expressed as percentages per 100 counted cells. The study determined the type of cytological picture (Ivanusa et al., 2016; Widana et al., 2021), and the regenerative-degenerative index (RDI) (Kayem \& Karlov, 1977).

The work was carried out in the design of a simple randomized comparative controlled examination in parallel groups. The program SPSS Statistics 25 (IBM) was used for statistical processing of the obtained data. To study the relationship between qualitative features, conjugacy tables were built and the Pearson $\mathrm{x} 2$ criterion or the exact Fisher criterion was calculated. If there is a relationship between qualitative features, the proportions of features were additionally compared using the $\mathrm{z}$-score. The reliability of the differences between the groups by quantitative characteristics was assessed using the parametric Student $\mathrm{t}$-test and the nonparametric Mann-Whitney U test (Mann \& Whitney, 1947), for unrelated groups. For related groups, the parametric t-criterion for dependent samples and the nonparametric Wilcoxon signed-rank test were used (Kamayev, 1954). To assess the changes in the dynamics of quantitative indicators, the authors used an analysis of variance with repeated measurements assigning a time factor and a group. As a result of the analysis of variance with repeated measurements, hypotheses were tested: whether the change in indicators over time is significant, whether there is a difference between the groups, and also if there is a statistically significant interaction of the time factor and the group. The latter hypothesis allowed proving the difference in the change of the controlled indicators over time, depending on the group. The differences were considered statistically significant when the probability value was less than 0.05 for a two-sided critical region. 


\section{Results and Discussions}

The median microbial contamination of wounds at admission in patients of the main group was $50 \times 108$ $\mathrm{cfu} / \mathrm{ml}$ of wound fluid (interquartile range from $40 \times 108$ to $65 \times 108 \mathrm{cfu} / \mathrm{ml}$ of wound fluid) in the comparison group $-50 \times 108 \mathrm{cfu} / \mathrm{ml}$ of wound fluid (interquartile range from $40 \times 108$ to $60 \times 108 \mathrm{cfu} / \mathrm{ml}$ of wound fluid, $\mathrm{p}=0.57$ ). 5 days after surgery, the median microbial contamination of wounds in the main group of patients was $6 \times 103 \mathrm{cfu} / \mathrm{ml}$ of wound fluid (interquartile range from $5 \times 103$ to $7.5 \times 103 \mathrm{cfu} / \mathrm{ml}$ of wound fluid). In the main group, according to the Wilcoxon criterion, statistically significant differences were found between the results for this indicator, $\mathrm{p}<0.001$. In the comparison group on day 5 , the median microbial contamination of wounds was $5 \times 105 \mathrm{cfu} / \mathrm{ml}$ of wound fluid (interquartile range from $3 \times 105$ to $6 \times 105 \mathrm{cfu} / \mathrm{ml}$ of wound fluid) (Figure 1).

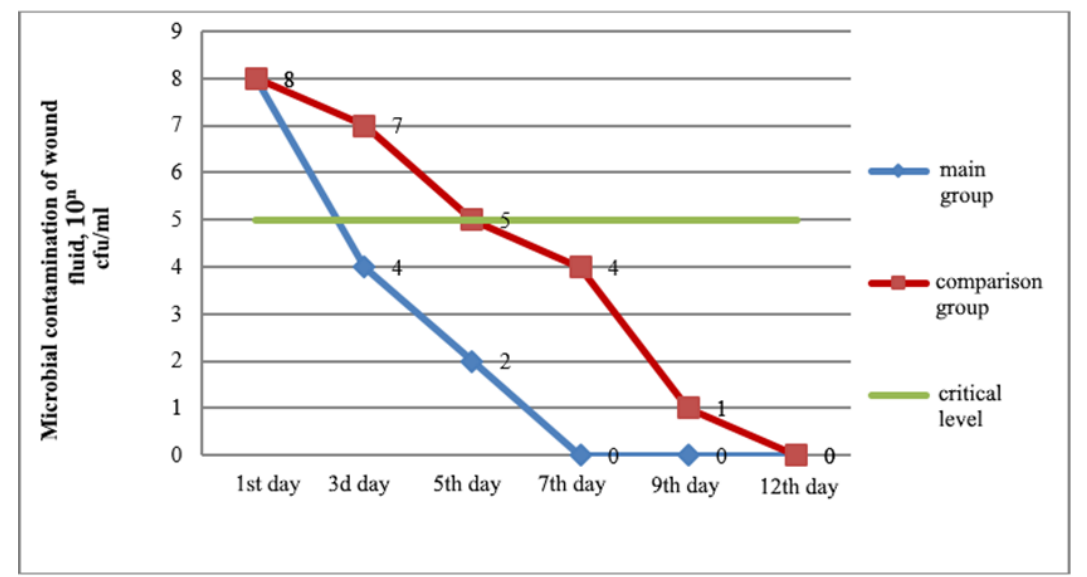

Figure 1. Dynamics of bacterial contamination of wound exudate in patients with purulent-necrotic complications of DFS in the studied groups

According to the pH-metry of wound exudate during surgery, patients of the main group had acidosis in the wound (median and interquantile range) 5.2 from 5.0 to 5.4, in the comparison group - 5.2 from 5.0 to 5.6; according to Mann-Whitney $\mathrm{U}$ test $\mathrm{p}=0.99$. In the course of treatment, leaching of wound exudate $\mathrm{pH}$ above 6.5-6.6) in patients of the main group was observed on the 4th-5th day (according to the Wilcoxon signedrank test (Wilcoxon, 1947) [35], the results differ, $p<0.001$ ), and in the patients of the comparison group, the same results were noted on the 8-9th day after the surgery (Figure 2).
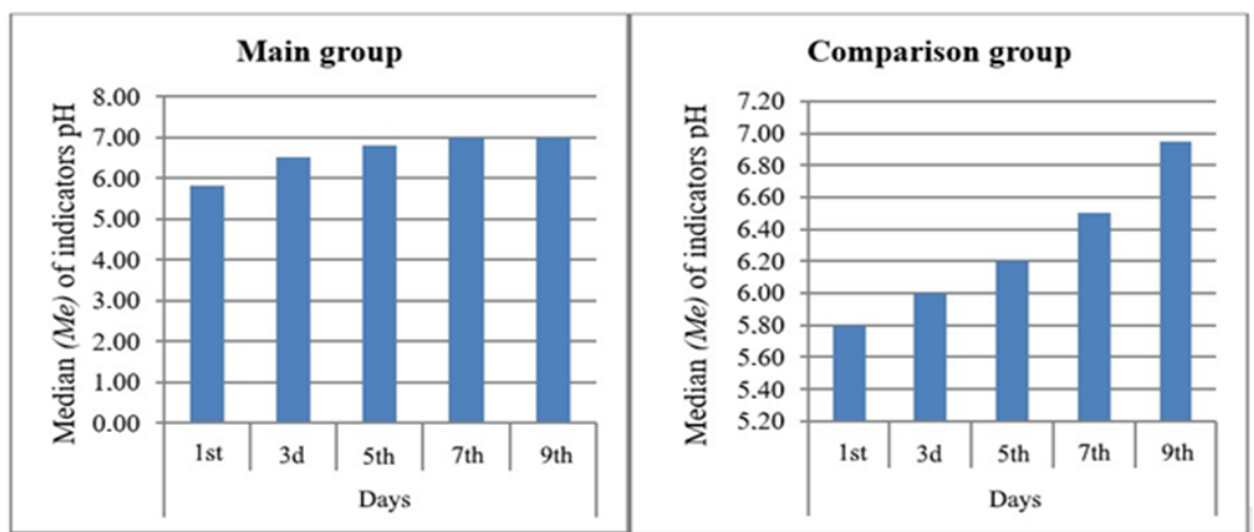

Figure 2. Dynamics of pH-metry results (Me) in patients with purulonecrotic complications of DFS in the studied groups

Sergeev, V. A., Glukhov, A. A., Sorokin, A. S., Zhuchkov, S. A., Gorokhov, A. V., \& Troshkina, E. N. (2021). Clinical-functional and morphological parameters of purulonecrotic foci healing in diabetic foot syndrome using programmable sanitation technologies. International Journal of Health Sciences, 5(3), 260-275. https://doi.org/10.53730/ijhs.v5n3.1495 
In patients of both study groups, the predominance of degenerative neutrophils (DN) (82.6 $\pm 3.2 \%)$ was observed in cytological smears at the time of randomization, and there were very few preserved forms of leukocytes. The regenerative-degenerative index (RDI) was significantly lower than the one $(0.2 \pm 0.1)$. The cytological picture was characterized by a degenerative-necrotic type of cell reaction. The microflora was in large quantities, mainly extracellularly, but sometimes it was possible to meet it intracellularly in a state of incomplete or perverted phagocytosis. Accumulations of necrotic masses and an amorphous tremelloid intercellular substance were observed in the preparations (Figure 3).

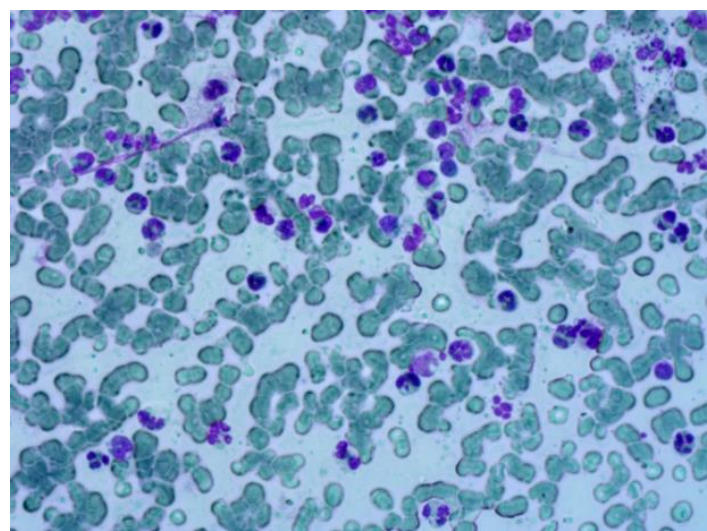

Figure 3. A fragment of a cytogram of a smear from the wound surface in patients with purulent complications of DFS in the study groups on the 1st day of treatment

The cytogram is dominated by degeneratively altered polymorphonuclear leukocytes, the microflora is in large numbers mainly extracellularly, there is an accumulation of necrotic masses and an amorphous tremelloid intercellular substance. Staining according to Romanovsky-Giemsa. Lens $\times 40$. The cellular composition of cytological smears in patients with purulent complications of DFS in the study groups at the time of randomization is presented in Table 4.

Table 4

The cellular composition of cytological smears in patients with purulent complications of DFS in the study groups at the time of randomization, in \% per 100 cells

\begin{tabular}{|c|c|c|c|c|c|c|}
\hline \multirow{2}{*}{$\begin{array}{l}\text { Cell } \\
\text { types }\end{array}$} & \multicolumn{2}{|c|}{ Main group } & \multicolumn{2}{|c|}{ Comparison group } & \multirow{2}{*}{$\begin{array}{l}\text { p-value of the } \\
\text { t-criterion }\end{array}$} & \multirow{2}{*}{$\begin{array}{l}\text { p-value of Mann- } \\
\text { Whitney U test }\end{array}$} \\
\hline & $\begin{array}{l}M \pm \sigma, \text { in } \% \\
\text { per } 100 \text { cells }\end{array}$ & Me (Q1;Q3) & $\begin{array}{l}M \pm \sigma, \text { in } \% \text { per } \\
100 \text { cells }\end{array}$ & Me (Q1;Q3) & & \\
\hline $\mathrm{BC}$ & $1.8 \pm 0.2$ & $1.8(1.7 ; 1.9)$ & $1.8 \pm 0.2$ & $1.7(1.6 ; 1.8)$ & 0.706 & 528.500 \\
\hline SN & $14.2 \pm 0.4$ & $\begin{array}{l}14.2 \\
(14.0 ; 14.4)\end{array}$ & $16.2 \pm 0.4$ & $\begin{array}{l}16.2 \\
(16.0 ; 16.2)\end{array}$ & 0.647 & 502.500 \\
\hline DN & $82.6 \pm 3.2$ & $\begin{array}{l}64.5 \\
(64.5 ; 72.4)\end{array}$ & $84.2 \pm 6.2$ & $\begin{array}{l}68.2 \\
(68.2 ; 72.4)\end{array}$ & 0.005 & 317.500 \\
\hline RDI & $0.2 \pm 0.1$ & $0.2(0.1 ; 0.2)$ & $0.2 \pm 0.1$ & $0.2(0.1 ; 0.2)$ & 0.976 & 558.000 \\
\hline $\mathrm{L}$ & $0.4 \pm 0.2$ & $0.4(0.3 ; 0.5)$ & $0.2 \pm 0.1$ & $0.2(0.1 ; 0.2)$ & 0.000 & 69.000 \\
\hline
\end{tabular}

*Note: BC - basilar cells, SN - segmented neutrophils, DN - degenerative neutrophils, RDI - regenerativedegenerative index, $\mathrm{L}$ - lymphocytes.

All parameters of the statistical assessment of the cellular composition of cytological smears on the first day of observation in both study groups are close in values ( $p>0.05)$, which allowed estimating the homogeneity of the groups. On the 5th day of treatment in the comparison group, the cytological picture in the smears changed slightly and corresponded to the degenerative-inflammatory type of cell reaction. In the main group, a statistically significant decrease in the number of destroyed neutrophils was observed in smears to $37.34 \pm 2.33 \%$, in contrast to the comparison group $-72.5 \pm 1.37 \%(\mathrm{p}<0.05)$. The regenerative-degenerative 
index on the 5 th day in the main group was $1.19 \pm 0.09$, which statistically significantly exceeded this indicator in the comparison group $-0.49 \pm 0.04(p<0.05)$. In the comparison group, smears on the 5 th day of granulation tissue elements were isolated, and in the main group among leukocytes, the dynamics of active macrophages $(3.59 \pm 0.25 \%)$ and fibroblasts $(3.21 \pm 0.31 \%)$ looked significantly very optimistic $(\mathrm{p}<0.05)$, a group of cells of young connective tissue in the form of fibroblasts, fibroblasts, fibrous fibres were discovered (Hong et al., 2014; Cosson et al., 2006; Romano et al., 1998). All this confirmed the presence of a reparative potential in the wound, and the cytological picture corresponded to the inflammatory or inflammatory-regenerative type. Figures 4 and 5 demonstrate fragments of cytological smears from the wound surface in patients with purulent complications of DFS in the study groups on the 5th day of treatment.

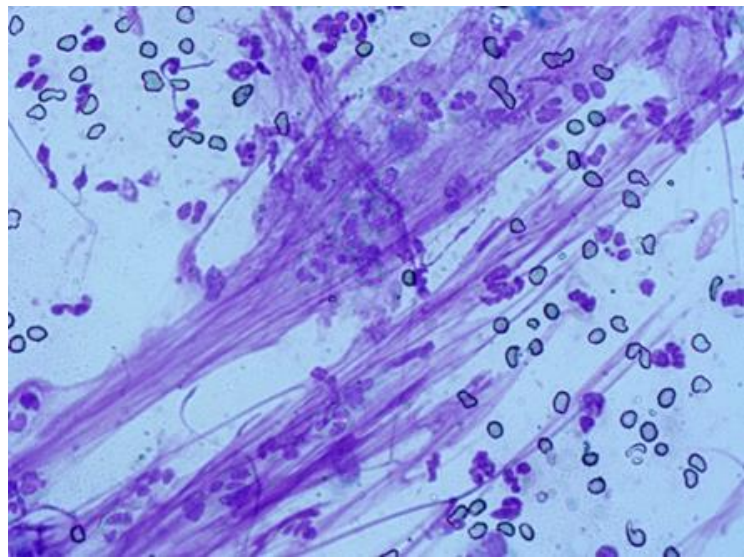

Figure 4. A fragment of a cytogram of a smear from the wound surface on the 5th day, the main group *Note: among neutrophils and polyblasts, fibrocytes, fibroblasts, fibrous fibres were found; RomanovskyGiemsa staining; lens $\times 40$.

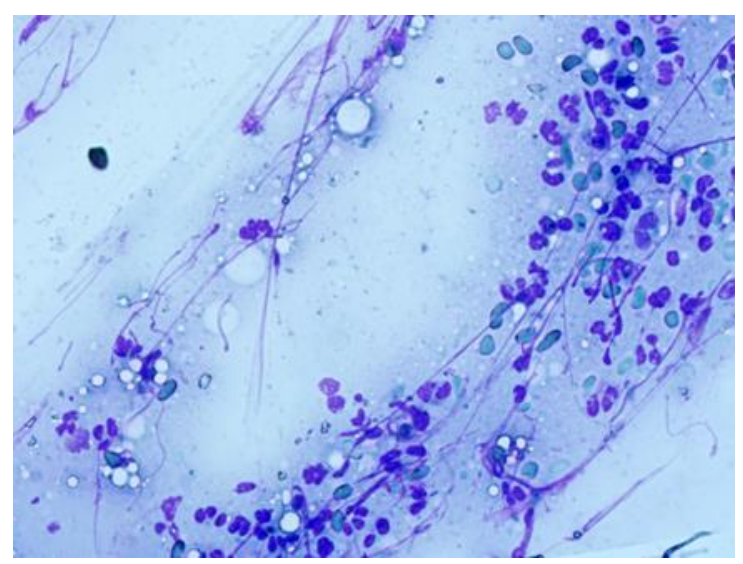

Figure 5. A fragment of a cytogram of a smear from the wound surface on the 5th day, a comparison group

*Note: single actively phagocytic leukocytes, macrophages, lymphocytes are observed; elements of granulation tissue are single; Romanovsky-Giemsa staining; lens $\times 40$.

On the 9th day of the postsurgical period in the comparison group, the cytological picture began to acquire features characteristic of regenerative processes and corresponded to the inflammatory-regenerative type of cellular reactions. This was expressed in a decrease in the number of all types of leukocytes $(p<0.05)$, there was a statistically significant increase in RDI $-0.90 \pm 0.03$, fibroblasts have appeared $-1.39 \pm 0.13 \%$, the number of macrophages increased $(2.21 \pm 0.19 \%)$. In the main group on the 9 th day of treatment, young elements of connective tissue and polyblasts predominated among the cellular elements, are located among the fibrous structures of the intercellular substance. The epithelium was presented in smears in the form of

Sergeev, V. A., Glukhov, A. A., Sorokin, A. S., Zhuchkov, S. A., Gorokhov, A. V., \& Troshkina, E. N. (2021). Clinical-functional and morphological parameters of purulonecrotic foci healing in diabetic foot syndrome using programmable sanitation technologies. International Journal of Health Sciences, 5(3), 260-275. https://doi.org/10.53730/ijhs.v5n3.1495 
cell layers, the microflora was absent, the nature of the cytograms corresponded to the regenerative type of cell reactions. Figures 6 and 7 demonstrate fragments of cytological smears from the wound surface in patients with purulent complications of DFS in the study groups on 9th day.

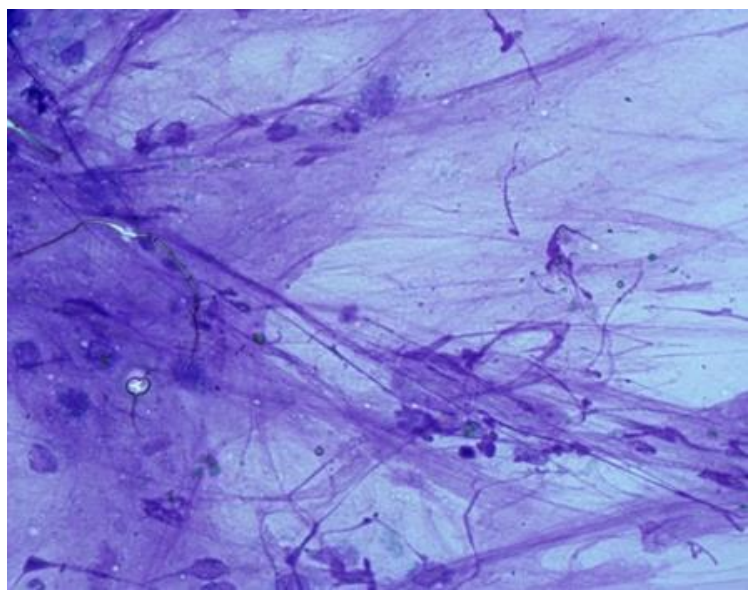

Figure 6. A fragment of a cytogram of a smear from the wound surface on the 9th day, the main group

*Note: young elements of connective tissue, fibroblasts, polyblasts, macrophages are located among the fibrous structures of the intercellular substance; the epithelium is represented as layers of cells; RomanovskyGiemsa staining; lens $\times 40$.

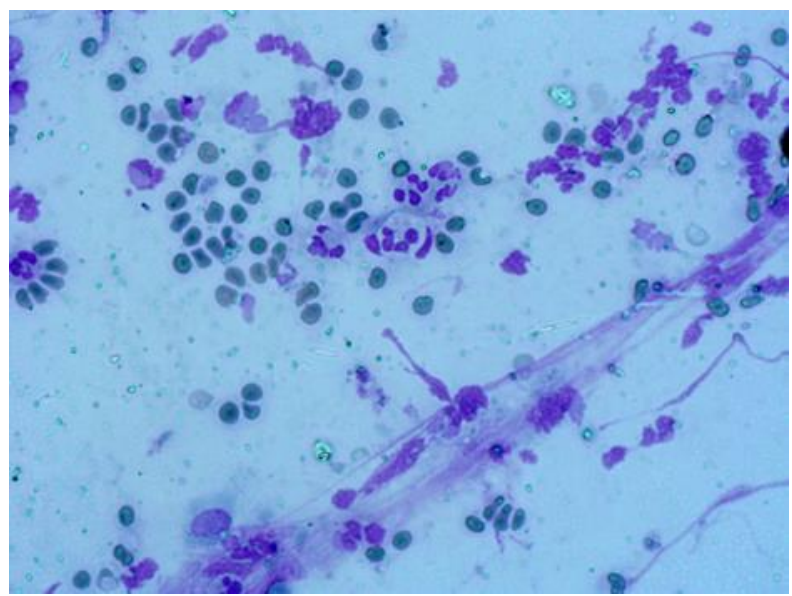

Figure 7. A fragment of a cytogram of a smear from the wound surface on the 9th day, a comparison group *Note: the number of mononuclear cells decreased, the number of polyblasts, fibroblasts, macrophages increased; delicate fibrous structures of the intercellular substance were observed; Romanovsky-Giemsa staining; lens $\times 40$.

The cellular composition of cytological smears in patients with purulent complications of DFS in the study groups on the 5th and 9 th days of treatment is presented in Table 5.

Table 5

The cellular composition of cytological smears in patients with purulent complications of DFS in the study groups $(\mathrm{M} \pm \sigma)$, in \% per 100 cells

\begin{tabular}{lllll}
\hline \multirow{2}{*}{ Cell types } & \multicolumn{2}{c}{ Main group } & \multicolumn{2}{c}{ Comparison group } \\
\cline { 2 - 5 } & 5 th day & 9th day & 5th day & 9th day \\
\hline DN & $37.34 \pm 2.33$ & $12.28 \pm 0.29$ & $72.5 \pm 1.37$ & $36.42 \pm 0.36$ \\
BC & $5.55 \pm 0.39$ & $3.63 \pm 0.18$ & $6.2 \pm 0.24$ & $8.09 \pm 0.84$
\end{tabular}




\begin{tabular}{lllll}
\hline SN & $38.69 \pm 1.33$ & $28.21 \pm 0.94$ & $28.96 \pm 2.25$ & $24.31 \pm 0.88$ \\
RDI & $1.19 \pm 0.09$ & $2.61 \pm 0.09$ & $0.49 \pm 0.04$ & $0.90 \pm 0.03$ \\
L & $4.79 \pm 0.24$ & $6.81 \pm 0.48$ & $0.77 \pm 0.23$ & $1.84 \pm 0.43$ \\
M & $3.59 \pm 0.25$ & $12.17 \pm 0.68$ & $0.17 \pm 0.06$ & $2.21 \pm 0.19$ \\
F & $3.21 \pm 0.31$ & $6.44 \pm 0.38$ & $0.12 \pm 0.02$ & $1.39 \pm 0.13$ \\
\hline
\end{tabular}

*Note: DN - degenerative neutrophils, BC - basilar cells, SN - segmented neutrophils, RDI - regenerativedegenerative index, $\mathrm{L}$ - lymphocytes, $\mathrm{M}$ - macrophages, $\mathrm{F}$ - fibroblasts.

For both groups, statistically significant changes in the cellular composition in the cytograms on the 1st and 9th days of treatment were proved, and in the main group, where programmable sanitation technologies were used, there was a faster decrease in the number of degenerative neutrophils, an increase in their preserved forms, a faster increase in RDI. The differences between the groups were statistically significant in general for the entire follow-up period $(\mathrm{p}<0.001)$. The presence of a significant interaction between the time factor and the group $(\mathrm{p}<0.001)$ was also established, in the main group by the 9 th day, the number of degenerative forms was significantly lower than in the comparison group $-12.28 \pm 0.29 \%$ and $36.42 \pm 0.36 \%$, respectively, the number of preserved forms of neutrophils was higher $-28.21 \pm 0.94 \%$ and $24.31 \pm 0.88 \%$, respectively. There was a faster increase in RDI on the 9th day in the main group compared to the comparison group $-2.61 \pm 0.09$ and $0.90 \pm 0.03$, respectively. This indicated more active phagocytosis, faster purification of the purulent cavity (Tareef et al., 2017; Heer et al., 2003; Berezin, 2017).

To assess the reparative potential of purulent wounds, a cytological assessment of the quantitative composition of lymphocytes, macrophages, and fibroblasts was carried out in the study groups on the 1st and 9th days of treatment. A significant interaction was established between the time factor and the group $(\mathrm{p}<0.001)$, in the main group by the 9 th day, the number of lymphocytes was significantly higher than in the comparison group $-7.5 \pm 0.6 \%$ and $2.5 \pm 0.6 \%$, respectively, the number of macrophages was higher $12.17 \pm 0.68 \%$ and $2.21 \pm 0.19 \%$, respectively. Also, a faster increase in fibrocytes and fibroblasts was observed in the main group $-6.44 \pm 0.38 \%$ and $1.39 \pm 0.13 \%$, respectively. This indicated active regenerative processes in the wound in patients of the main group. In the main group, the length of stay in the hospital of patients with purulonecrotic complications in DFS (median and interquartile range) was 21 bed-days (from 21 to 23 beddays), in the comparison group - 29 bed-days (from 27 to 30 bed-days, $p<0.001$ based on Mann-Whitney U test (Mann \& Whitney, 1947). The immediate results of treatment were analyzed in 106 operated patients (Table 6).

Table 6

Immediate results of treatment of patients with purulonecrotic complications of DFS in the studied groups

\begin{tabular}{|c|c|c|c|c|c|c|c|c|c|}
\hline & & $\begin{array}{l}\text { There is } \\
\text { an } \\
\text { outcome }\end{array}$ & $\begin{array}{l}\text { There is } \\
\text { no } \\
\text { outcome }\end{array}$ & AR & RR & CI RR & OR & CI OR & $\mathrm{F}$ \\
\hline \multirow{2}{*}{$\begin{array}{l}\text { Postsurgical } \\
\text { mortality }\end{array}$} & Main group & 3 & 52 & 0.055 & \multirow[t]{2}{*}{0.556} & 0.140 & \multirow[t]{2}{*}{0.531} & 0.098 & \multirow[t]{2}{*}{0.477} \\
\hline & $\begin{array}{l}\text { Comparison } \\
\text { group }\end{array}$ & 5 & 46 & 0.098 & & 2.211 & & 3.899 & \\
\hline \multirow{2}{*}{$\begin{array}{l}\text { Purulent } \\
\text { complications }\end{array}$} & Main group & 5 & 50 & 0.091 & \multirow[t]{2}{*}{0.357} & 0.137 & \multirow[t]{2}{*}{0.292} & 0.064 & \multirow[t]{2}{*}{0.037} \\
\hline & $\begin{array}{l}\text { Comparison } \\
\text { group }\end{array}$ & 13 & 38 & 0.255 & & 0.930 & & 0.744 & \\
\hline \multirow[t]{2}{*}{ Amputation } & Main group & 4 & 51 & 0.073 & \multirow[t]{2}{*}{0.285} & 0.099 & \multirow[t]{2}{*}{0.229} & 0.072 & \multirow[t]{2}{*}{0.016} \\
\hline & $\begin{array}{l}\text { Comparison } \\
\text { group }\end{array}$ & 13 & 38 & 0.255 & & 0.819 & & 0.842 & \\
\hline \multirow{2}{*}{$\begin{array}{l}\text { The supporting } \\
\text { function of the } \\
\text { foot was } \\
\text { preserved in }\end{array}$} & Main group & 45 & 7 & 0.865 & \multirow[t]{2}{*}{1.327} & 1.047 & \multirow[t]{2}{*}{3.429} & 1.260 & \multirow[t]{2}{*}{0.017} \\
\hline & $\begin{array}{l}\text { Comparison } \\
\text { group }\end{array}$ & 30 & 16 & 0.652 & & 1.681 & & 9.331 & \\
\hline
\end{tabular}

Sergeev, V. A., Glukhov, A. A., Sorokin, A. S., Zhuchkov, S. A., Gorokhov, A. V., \& Troshkina, E. N. (2021). Clinical-functional and morphological parameters of purulonecrotic foci healing in diabetic foot syndrome using programmable sanitation technologies. International Journal of Health Sciences, 5(3), 260-275. https://doi.org/10.53730/ijhs.v5n3.1495 
discharged

patients

*Note: AR - absolute risk, RR - relative risk, CI RR - 95\% confidence interval for relative risk, OR - odds ratio, CI OR - 95\% confidence interval for odds ratio, F - p-value of the exact Fisher criterion (two-way critical region).

Postsurgical mortality in the main group of patients was 5.5\%, in the comparison group - 9.8\%. All fatal cases were noted after high amputations. At the significance level of $p=0.477$, the hypothesis was adopted that there were no differences between the groups in the number of fatal cases. Purulent complications were observed in the main group of patients in 5 cases (9.1\%), and in the comparison group - in 13 cases (25.5\%, p=0.037). High amputations were performed in patients of the main group in 4 cases $(7.3 \%)$, including at the level of the upper third of the lower leg in two cases, at the level of the hip also in two cases. In the comparison group, amputation was performed in 13 cases $(25.5 \%, \mathrm{p}=0.016)$, of which the lower leg was amputated in 5 cases, the hip was amputated in 8 cases. The supporting function of the foot was preserved in the main study group in 45 discharged patients (86.5\%), in the comparison group - in 30 patients, which was $65.2 \%(\mathrm{p}=0.017)$.

Over the past 10 years, according to open literature sources, there has been a persistent trend towards an increase in the number of works devoted to purulonecrotic complications of DFS. This proves not only the unflagging interest in this problem but also clearly demonstrates the lack of a reasoned breakthrough approach in determining therapeutic tactics for this pathology. As is known, wounds heal according to uniform biological laws, regardless of the cause and nature, and in their development, they undergo the stages of inflammation, regeneration, and epithelialization. The failures and insufficient effectiveness of the treatment of purulonecrotic foci in DFS are due to disturbed local tissue response to the introduction of an infectious agent, high bacterial contamination, and a deficiency of most growth factors involved in the repair process. Currently, experts consider the emergence of innovative methods of intraoperative and postoperative rehabilitation of purulent foci, overcoming antibiotic resistance and increasing the effectiveness of systemic antibacterial therapy, the use of targeted correction of immunotherapy to be promising areas in the treatment of purulent complications in DFS (Stupin et al., 2019; Zaytseva et al., 2014; Kayem \& Karlov, 1977; Davydov et al., 1990; Sergeev \& Glukhov,2020).

Early closure of the wound with sutures in the main group, the use of active drainage under conditions of a minimally pronounced inflammatory reaction in the purulent focus considerably accelerated the reparative processes, creating conditions for the development and completion of the regeneration phase. On the 9 th day from the start of treatment, young connective tissue elements, polyblasts, dominated among the cellular elements in the main group, is located among the fibrous structures of the intercellular substance. The RDI in the main group was significantly different compared to the comparison group $-2.61 \pm 0.09$ and $0.90 \pm 0.03$, respectively $(\mathrm{p}<0.001)$. The epithelium was presented in smears in the form of cell layers, the microflora was absent, the nature of the cytograms corresponded to the regenerative type of cell reactions. The immediate results of treatment were better in patients of the main group compared to the comparison group. The length of stay in the hospital for the patients of the main group was statistically significantly lower $(p<0.001)$, the number of purulent complications was significantly lower $(\mathrm{p}=0.014)$ than in the comparison group, and the support function of the foot in the patients of the main group was preserved in a greater percentage of cases $(p=0.023)$. There was also a significant increase in the frequency of high amputations in the comparison group compared to the main group of patients $(\mathrm{p}=0.026)$.

\section{Conclusion}

In this study, the authors aimed to evaluate the clinical, functional, and morphological parameters of the healing of purulonecrotic foci in DFS with the use of programmable rehabilitation technologies compared with conventional methods of treatment. The use of programmable sanitation technologies allowed creating conditions for better sanitation of the purulent focus, led to a reduction in all phases of the wound process. Surgical treatment of a purulent focus, long-term irrigation of the wound cavity in the postsurgical period, software for the drainage process using negative pressure in the purulent cavities made it possible to clean the wound from non-viable tissues, inflammatory mediators, and cytokines in a short time. During the study, it 
was proved that the decrease in bacterial contamination below the critical values in the main group was noted at an earlier time $(\mathrm{p}<0.001)$, and the leaching of wound exudate in the main group was also observed faster than in the comparison group $(\mathrm{p}<0.001)$. In cytological smears on the 5 th day from the start of treatment, a statistically significant decrease in the number of degenerative neutrophils was observed in the main group to $37.34 \pm 2.33 \%(\mathrm{p}<0.05)$, and the RDI was $1.19 \pm 0.09$, which statistically exceeded this indicator in the comparison group $(\mathrm{p}<0.05)$. There was also a statistically significant increase in active macrophages $(\mathrm{p}<0.05)$, and groups of cells of young connective tissue were found among neutrophils. The cytological picture on the 5 th day of treatment corresponded to the inflammatory-regenerative type. All this confirmed the relief of the stage of inflammation and the transition of the wound process to the stage of regeneration, in contrast to the comparison group, where a low intensity of cellular reactions in the wound was noted.

Evaluation of the healing of purulonecrotic foci in diabetic foot syndrome without the phenomena of critical ischemia using programmable rehabilitation technologies showed that they differ in their morphological characteristics and repair potential from purulent wounds in conventional treatment. The cytological smears of the main group identified a higher rate of cellular reactions in the wound: a rapid decrease in degenerative forms of neutrophils, the occurrence of active macrophages, and young connective tissue cells at an earlier time, which indicated active regenerative processes in the wound. This made it possible to sanitize purulent foci in a shorter time and more efficiently, normalize the wound environment, reduce the time of transition of the wound process from the phase of inflammation to the phase of regeneration, which contributed to reducing the time of hospitalization and improving the immediate results of treatment.

\section{Acknowledgments}

We are grateful to two anonymous reviewers for their valuable comments on the earlier version of this paper.

Sergeev, V. A., Glukhov, A. A., Sorokin, A. S., Zhuchkov, S. A., Gorokhov, A. V., \& Troshkina, E. N. (2021). Clinical-functional and morphological parameters of purulonecrotic foci healing in diabetic foot syndrome using programmable sanitation technologies. International Journal of Health Sciences, 5(3), 260-275. https://doi.org/10.53730/ijhs.v5n3.1495 


\section{References}

Armstrong, D. G., Boulton, A. J., \& Bus, S. A. (2017). Diabetic foot ulcers and their recurrence. New England Journal of Medicine, 376(24), 2367-2375.

Bakker, K., Apelqvist, J., Lipsky, B. A., Van Netten, J. J., Schaper, N. C., \& International Working Group on the Diabetic Foot (IWGDF). (2016). The 2015 IWGDF guidance documents on prevention and management of foot problems in diabetes: development of an evidence-based global consensus. Diabetes/metabolism research and reviews, 32, 2-6.

Baltzis, D., Eleftheriadou, I., \& Veves, A. (2014). Pathogenesis and treatment of impaired wound healing in diabetes mellitus: new insights. Advances in therapy, 31(8), 817-836.

Berezin, A. E. (2017). Endothelial progenitor cells dysfunction and impaired tissue reparation: the missed link in diabetes mellitus development. Diabetes \& Metabolic Syndrome: Clinical Research \& Reviews, 11(3), 215220. https://doi.org/10.1016/j.dsx.2016.08.007

Bordianu, A., Bobircă, F., \& Pătraşcu, T. (2018). Skin Grafting in the Treatment of Diabetic Foot Soft Tissue Defects. Chirurgia (Bucharest, Romania: 1990), 113(5), 644-650.

Brancato, S. K., \& Albina, J. E. (2011). Wound macrophages as key regulators of repair: origin, phenotype, and function. The American journal of pathology, 178(1), 19-25. https://doi.org/10.1016/j.ajpath.2010.08.003

Braun, L. R., Fisk, W. A., Lev-Tov, H., Kirsner, R. S., \& Isseroff, R. R. (2014). Diabetic foot ulcer: an evidencebased treatment update. American journal of clinical dermatology, 15(3), 267-281.

Carchi, J. A. Y. ., Catagua, T. C. M. ., Rivera, D. G. B. ., Mera, V. B. ., \& Rosario, M. del . (2021). From beginner to expert, experience of the rotating nursing intern in pre-professional practice. International Journal of Health Sciences, 5(2), 111-117.

Ceriello, A. (2006). Oxidative stress and diabetes-associated complications. Endocrine Practice, 12, 60-62. https://doi.org/10.4158/EP.12.S1.60

Cosson, E., Benchimol, M., Carbillon, L., Pharisien, I., Pariès, J., Valensi, P., ... \& Attali, J. R. (2006). Universal rather than selective screening for gestational diabetes mellitus may improve fetal outcomes. Diabetes \& metabolism, 32(2), 140-146. https://doi.org/10.1016/S1262-3636(07)70260-4

Davydov, I. A., Larichev, A. B., \& Abramov, A. I. (1990). Substantiation of using forced early secondary suture in the treatment of suppurative wounds by the method of vacuum therapy. Vestnik khirurgii imeni II Grekova, 144(3), 126-128.

Dedov, I. I., Shestakova, M. V., \& Vikulova, O. K. (2017). Epidemiology of diabetes mellitus in Russian Federation: clinical and statistical report according to the federal diabetes registry. Diabetes mellitus, 20(1), 13-41.

Dinh, T., Tecilazich, F., Kafanas, A., Doupis, J., Gnardellis, C., Leal, E., ... \& Veves, A. (2012). Mechanisms involved in the development and healing of diabetic foot ulceration. Diabetes, 61(11), 2937-2947.

Duzgun, A. P., Satır, H. Z., Ozozan, O., Saylam, B., Kulah, B., \& Coskun, F. (2008). Effect of hyperbaric oxygen therapy on healing of diabetic foot ulcers. The Journal of foot and ankle surgery, 47(6), 515-519. https://doi.org/10.1053/j.jfas.2008.08.002

Eskes, A. M., Gerbens, L. A., van der Horst, C. M., Vermeulen, H., \& Ubbink, D. T. (2011). Is the red-yellow-black scheme suitable to classify donor site wounds? An inter-observer analysis. Burns, 37(5), 823-827. https://doi.org/10.1016/j.burns.2010.12.019

Falanga, V. (2005). Wound healing and its impairment in the diabetic foot. The Lancet, 366(9498), 1736-1743. https://doi.org/10.1016/S0140-6736(05)67700-8

Galstyan, G. R., Vikulova, O. K., Isakov, M. A., Zheleznyakova, A. V., Serkov, A. A., \& Egorova, D. N. (2018). Epidemiology of diabetic foot syndrome and lower limb amputations in the Russian Federation according to the Federal Register of Diabetes Patients in 2013-2016. Sakharny Diabet, 21(3), 170-7.

Guariguata, L., Whiting, D., Weil, C., \& Unwin, N. (2011). The International Diabetes Federation diabetes atlas methodology for estimating global and national prevalence of diabetes in adults. Diabetes research and clinical practice, 94(3), 322-332. https://doi.org/10.1016/j.diabres.2011.10.040

Han, T., Wang, H., \& Zang, Y. Q. (2012). Combining platelet-rich plasma and extracellular matrix-derived peptides promote impaired cutaneous wound healing in vivo. J Craniofac Surg, 23(2), 439.

Heer, R., Shrimankar, J., \& Griffith, C. D. M. (2003). Granulomatous mastitis can mimic breast cancer on clinical, radiological or cytological examination: a cautionary tale. The breast,12(4), 283-286. https://doi.org/10.1016/S0960-9776(03)00032-8 
Hong, S., Lu, Y., Tian, H., Alapure, B. V., Wang, Q., Bunnell, B. A., \& Laborde, J. M. (2014). Maresin-like lipid mediators are produced by leukocytes and platelets and rescue reparative function of diabetes-impaired macrophages. Chemistry \& biology, 21(10), 1318-1329. https://doi.org/10.1016/j.chembiol.2014.06.010

Ivanov, D.P., Serebryakova, O.V., \& Ivanov, P.A. (2019). Instrumental Research Methods In Diagnostics Of Ischemic Form Of Diabetic Foot Syndrome. Transbaikal Medical Bulletin , (2), 126-138.

Ivanusa, S. Y., Risman, B. V., \& Ivanov, G. G. (2016). Modern ideas about methods of assessment the course of the wound process in patients with purulo-necrotic complications of the diabetic foot syndrome. Herald of the Russian Military Medical Academy= Vestnik rossijskoj voennoj medicinskoj akademii, 54, 190-194.

Jang, M. Y., Hong, J. P., Bordianu, A., \& Suh, H. S. (2015). Using a contradictory approach to treat a wound induced by hematoma in a patient with antiphospholipid antibody syndrome using negative pressure wound therapy: lessons learnt. The international journal of lower extremity wounds, 14(3), 303-306.

Kaem, R. I., \& Karlov, V. A. (1977). The morphology of a purulent wound closed by a suture. In Proceedings of the I All-Union Conference on Wounds and Wound Infections. Moscow: Medicina (pp. 7-8).

Kamayev, M.F. (1954). Types of cytograms in a superficial biopsy of the wound. In: Collection of works of the Odessa Medical Institute named after N. I. Pirogov, (pp. 267-276). Kyiv: Odessa Medical Institute named after N. I. Pirogov.

Koziel, H., \& Koziel, M. J. (1995). Pulmonary complications of diabetes mellitus: pneumonia. Infectious disease clinics of North America, 9(1), 65-96. https://doi.org/10.1016/S0891-5520(20)30641-3

Kurtieva, S., Nazarova, J., \& Mullajonov, H. (2021). Features of endocrine and immune status in adolescents with vegetative dystonia syndrome. International Journal of Health Sciences, 5(2), 118-127.

Kuzin, M. I., \& Kostyuchenok, B. M. (1990). Wounds and wound infection. Meditsina, Moscow, 169.

Lacci, K. M., \& Dardik, A. (2010). Platelet-rich plasma: support for its use in wound healing. The Yale journal of biology and medicine, 83(1), 1.

Larichev, A.B., Shishlo, V.K., Lisovskiy, A.V., \& Chistyakov, A.L. (2011). Wound infection prevention and morphological aspects of aseptic wound healing. Journal of experimental and clinical surgery , 4 (4), 728733.

Li, Z., Guo, S., Yao, F., Zhang, Y., \& Li, T. (2013). Increased ratio of serum matrix metalloproteinase-9 against TIMP-1 predicts poor wound healing in diabetic foot ulcers. Journal of Diabetes and its Complications, 27(4), 380-382. https://doi.org/10.1016/j.jdiacomp.2012.12.007

Liu, Y., Min, D., Bolton, T., Nubé, V., Twigg, S. M., Yue, D. K., \& McLennan, S. V. (2009). Increased matrix metalloproteinase-9 predicts poor wound healing in diabetic foot ulcers. Diabetes care, 32(1), 117-119.

Mann, H. B., \& Whitney, D. R. (1947). On a test of whether one of two random variables is stochastically larger than the other. The annals of mathematical statistics, 50-60.

Mitish, V. A., Paskhalova, Y. S., \& Eroshkin, I. A. (2014). Purulent necrotic lesions in the neuroischemic form of diabetic foot syndrome. Surgery. Magazine them. NI Pirogov, 1, 48-53.

Nemec, A., Dijkshoorn, L., Cleenwerck, I., De Baere, T., Janssens, D., van der Reijden, T. J., ... \& Vaneechoutte, M. (2003). Acinetobacter parvus sp. nov., a small-colony-forming species isolated from human clinical specimens. International journal of systematic and evolutionary microbiology, 53(5), 1563-1567.

Nickerson, S. (2018). Improving outcomes in recurrent and other new foot ulcers after healed plantar forefoot diabetic ulcer. Wound repair and regeneration: official publication of the Wound Healing Society [and] the European Tissue Repair Society, 26(1), 108-109.

Ray, J. A., Valentine, W. J., Secnik, K., Oglesby, A. K., Cordony, A., Gordois, A., ... \& Palmer, A. J. (2005). Review of the cost of diabetes complications in Australia, Canada, France, Germany, Italy and Spain. Current medical research and opinion, 21(10), 1617-1629.

Romano, G., Moretti, G., Di Benedetto, A., Giofre, C., Di Cesare, E., Russo, G., ... \& Cucinotta, D. (1998). Skin lesions in diabetes mellitus: prevalence and clinical correlations. Diabetes research and clinical practice, 39(2), 101-106. https://doi.org/10.1016/S0168-8227(97)00119-8

Sergeev, V.A. (2018). Utility model patent No. 176572. Device for pumping and suction of liquid.

Sergeev, VA, \& Glukhov, AA (2020). Vascular medicine. Journal of Vascular Medicine , 17 (3), 13-17.

Stupin, V. A., Silina, E. V., Koreyba, K. A., \& Goryunov, S. V. (2019). Diabetic foot syndrome (epidemiology, pathophysiology, diagnosis and treatment). M.: Litterra.

Sergeev, V. A., Glukhov, A. A., Sorokin, A. S., Zhuchkov, S. A., Gorokhov, A. V., \& Troshkina, E. N. (2021). Clinical-functional and morphological parameters of purulonecrotic foci healing in diabetic foot syndrome using programmable sanitation technologies. International Journal of Health Sciences, 5(3), 260-275. https://doi.org/10.53730/ijhs.v5n3.1495 
Tareef, A., Song, Y., Huang, H., Wang, Y., Feng, D., Chen, M., \& Cai, W. (2017). Optimizing the cervix cytological examination based on deep learning and dynamic shape modeling. Neurocomputing, 248, 28-40. https://doi.org/10.1016/j.neucom.2017.01.093

Wagner, F. W. (1979). A classification and treatment program for diabetic, neuropathic, and dysvascular foot problems. Instr Course Lect, 28(1), 143-65.

Wilcoxon, F. (1947). Probability tables for individual comparisons by ranking methods. Biometrics, 3(3), 119122.

Widana, I.K., Sumetri, N.W., Sutapa, I.K., Suryasa, W. (2021). Anthropometric measures for better cardiovascular and musculoskeletal health. Computer Applications in Engineering Education, 29(3), 550561. https://doi.org/10.1002/cae.22202

Yusupova, S., Nabiyev, M.K. \& Saykhunov, K.D. (2017). Comparative analysis of the results of a comprehensive operative-medical treatment of patients with complicated forms of diabetic foot syndrome. Bulletin of Avicenna, 19(2), 203-208.

Zaytseva, E. L., Doronina, L. P., Molchkov, R. V., Voronkova, I. A., Mitish, V. A., \& Tokmakova, A. Y. E. (2014). Effect of negative pressure therapy on repair of soft tissues of the lower extremities in patients with neuropathic and neuroischaemic forms of diabetic foot syndrome. Diabetes mellitus, 17(3), 113-121.

Zemskov, M. A., Khoroshilov, A. A., Il'ina, E. M., \& Domnich, O. A. (2011). Peculiarities of changes of immune status in chronic infl ammatory diseases. Vestnik Eksperimental'noi i Klinicheskoi Khirurgii, 4(3), 468-472.

Zimny, S., Schatz, H., \& Pfohl, M. (2002). Determinants and estimation of healing times in diabetic foot ulcers. Journal of Diabetes and its Complications, 16(5), 327-332. https://doi.org/10.1016/S10568727(01)00217-3

\section{Biography of Authors}

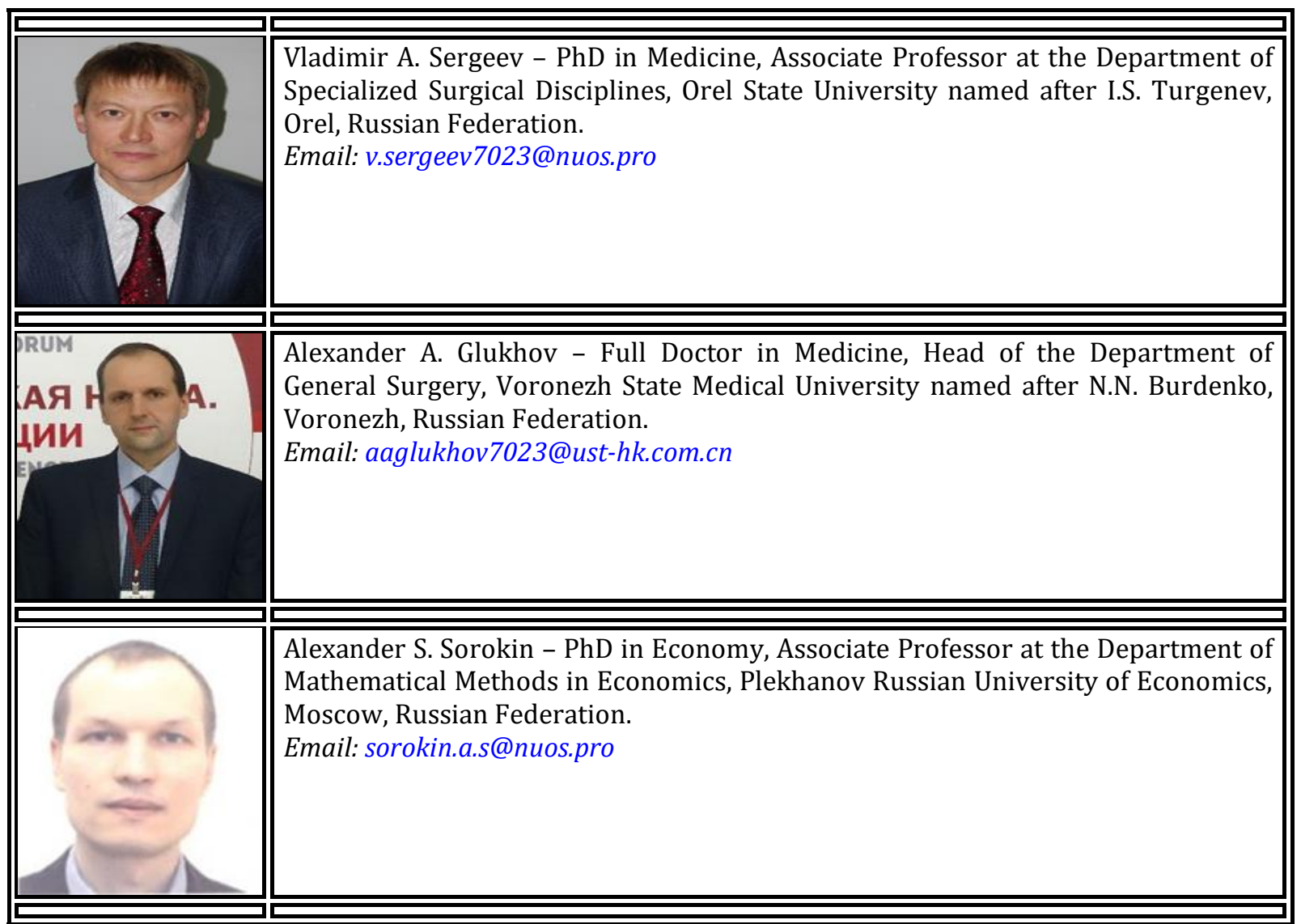




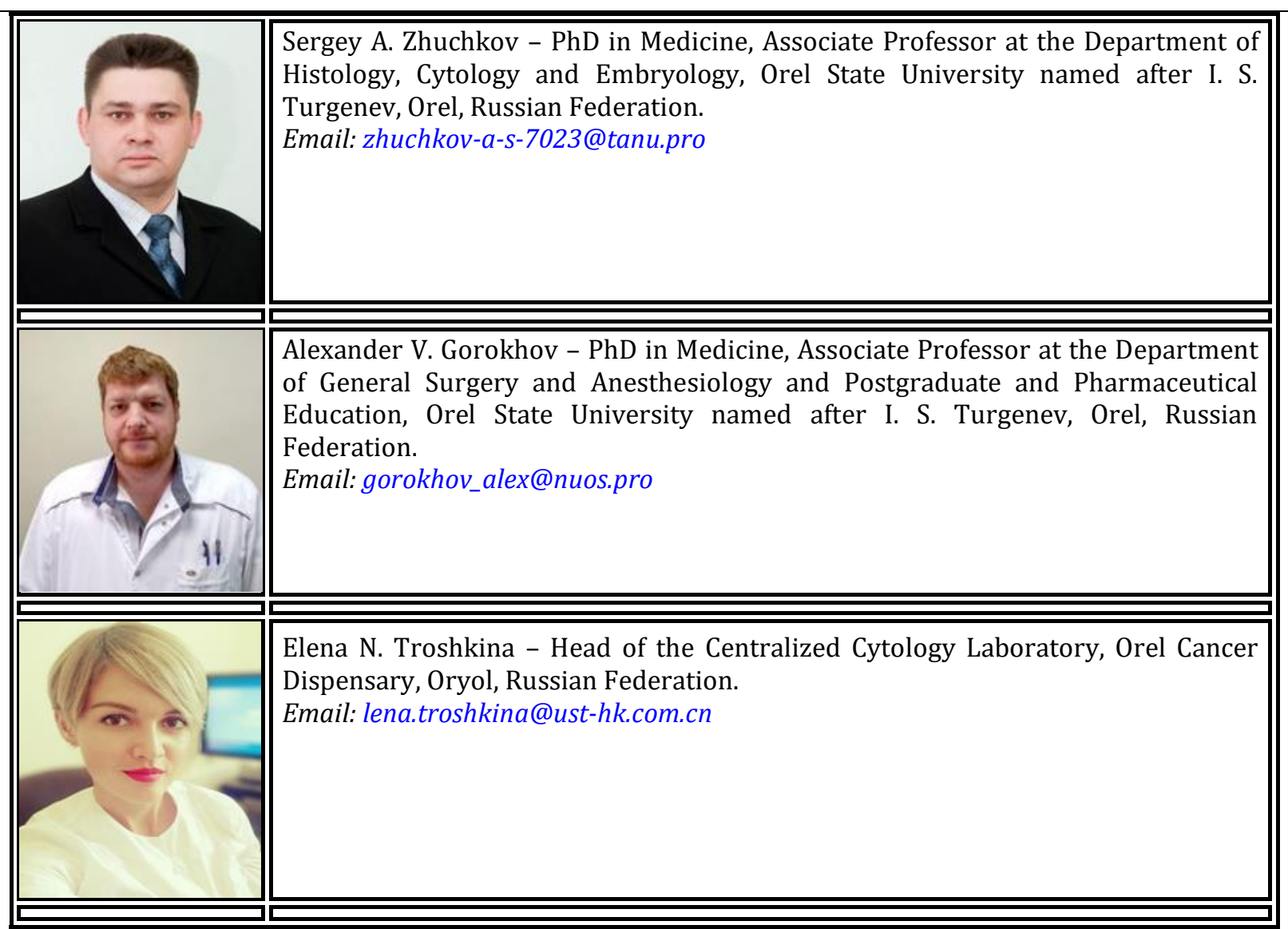

Sergeev, V. A., Glukhov, A. A., Sorokin, A. S., Zhuchkov, S. A., Gorokhov, A. V., \& Troshkina, E. N. (2021). Clinical-functional and morphological parameters of purulonecrotic foci healing in diabetic foot syndrome using programmable sanitation technologies. International Journal of Health Sciences, 5(3), 260-275. https://doi.org/10.53730/ijhs.v5n3.1495 